\title{
FATIGUE LIFE ASSESSMENT OF PRESTRESSED MATERIAL
}

\begin{abstract}
M. Balda*
Abstract: The contribution deals with a problem of estimating fatigue lives of machine parts subjected simultaneously to static and dynamic loading. A new method of estimating residual fatigue lives of materials with exponential SN curves under a high prestress is presented, which avoids expensive fatigue tests other than those with zero mean stress.
\end{abstract}

Keywords: fatigue, fatigue life, SN curve, damage

\section{Introduction}

Fatigue of materials is a very complicated phenomenon, which influences seriously the quality of structures. The bigger the structure is, the more important are the consequences of possible fatigue damages. The typical structures, in which any fatigue cracks should not occur, are turbomachines. Any unexpected breakdown caused by the fatigue generates extreme losses of energy production. This is the reason why producers of turbomachinery devote enormous care to a design of fatigue-save parts of a machine and to material testing. To common tests belong also fatigue tests of most exposed parts of the machine, blades of a turbine.

\section{Material testing}

Turbine blades of big turbomachines are long with twisted profiles along the lengths. Their material is tested in accordance with standards (ČSNI, 1973, 1978) by using set of specimens. There are many material tests, nevertheless, two of them are necessary for our subject of investigation, i.e. tensile test, and high cycle fatigue $(\mathrm{HCF})$ test.

\subsection{Tensile test}

The test serves for determining several static characteristics as the ultimate strength $R_{m}$, contractual yield strength $R_{p}$, and ultimate plastic strain $\varepsilon_{p}$. Even that these properties are necessary for the designer, for our purposes, the shape of the resulting trend is important. Figure 2 shows a graph of results of the tensile test of the material T671, which is used for a production of blades.

\subsection{Fatigue test}

A standard fatigue test is performed on a set of specimens, which are exposed to harmonic loading with a stress amplitude $s_{a_{k}}$. If a mean stress $s_{m_{k}}=0$, where $k$ is the specimen order number, the results is a set of fatigue lives $N_{a_{k}}$ belonging to $k$-th specimen. Each couple $\left(s_{a_{k}}, N_{a_{k}}\right)$ builds a point of the Wöhler curve in the case of $s_{m}=0$, what is a special case of general SN curves with $s_{m} \neq 0$.

\subsection{Fatigue data processing}

It has been decided just at the beginning of works that a software for experimental data processing will be built in MATLAB language (MathWorks, 2017), which can be applied also with the Open software GPU Octave (Eaton et al, 2017).

\footnotetext{
Prof. Ing. Miroslav Balda, DrSc.: Institute VZÚ Plzeň, Tylova 1581/46; 301 00, Plzeň; CZ, balda@ vzuplzen.cz
} 
Mr. Basquin have shown already in 1910 (Basquin, 1910) that the fatigue lives $N_{f}$ of steels are exponential functions of applied amplitudes of stress $s_{f}$, what means that Wöhler's curve becomes a straight line in the log-log diagram, which is used for low cycle fatigue (LCF) until now:

$$
s_{f}=s_{f}^{\prime}\left(2 N_{f}\right)^{b},
$$

Let us arrange the equation in a bit different form using equalities $N_{f}=N_{a}$ and $s_{f}=s_{a}$

$$
N_{a} s_{a}^{-1 / b}=s_{a}^{-1 / b} / 2
$$

The similar equation holds for high cycle fatigue (HCF)

$$
N_{a} s_{a}^{w}=C .
$$

By comparison of equations (2) and (3), the following equalities come out

$$
w=-\frac{1}{b} \quad \text { and } \quad C=s_{a}^{\prime w} / 2 .
$$

Tab. 1. Data of fatigue tests (Chvojan, 2003)

\begin{tabular}{crrr}
\hline \multicolumn{2}{c}{$\sigma_{m}=450$} & \multicolumn{2}{c}{$\sigma_{m}=600$} \\
\hline \hline$\sigma_{a}$ & \multicolumn{1}{c}{$N_{a}$} & $\sigma_{a}$ & \multicolumn{1}{c}{$N_{a}$} \\
\hline \hline 600 & 65200 & 500 & 218900 \\
500 & 371700 & 480 & 247700 \\
480 & 6530000 & 460 & 199000 \\
465 & 6075600 & 445 & 278000 \\
435 & 8131700 & 430 & 7552000 \\
420 & $>10^{7} \rightarrow$ & 420 & $>10^{7} \rightarrow$ \\
\hline
\end{tabular}

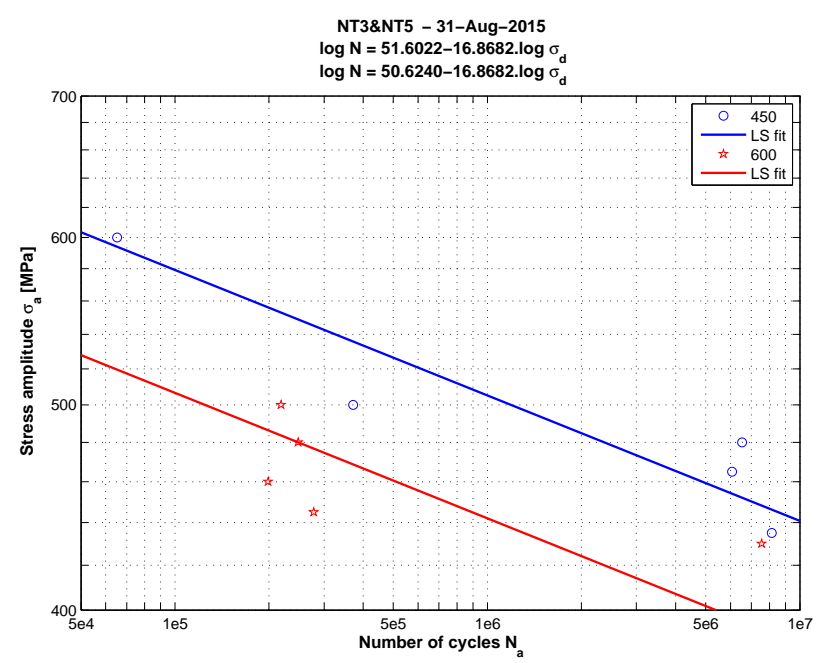

Fig. 1. SN curves with 2 prestresses

A logarithmic transformation of equation (3) yields

$$
\log N_{a}=\log C-w \log s_{a}
$$

beeing an equation of one straight line in logarithmic axes. This fact enables to process measured data by the linear regression, which finds the unknowns $w$ and $C$ by solving the overdetermined system of equations

$$
[\underbrace{\log \boldsymbol{s}_{\boldsymbol{a}}, \mathbf{1}}_{\boldsymbol{A}}] \underbrace{[-w, \log C]^{T}}_{\boldsymbol{c}}=\underbrace{\log \boldsymbol{N}_{\boldsymbol{a}}}_{\boldsymbol{b}},
$$

with a solution in the least-squares sense

$$
c=A^{+} b,
$$

where 1 is a vector of the same dimension as $\boldsymbol{b}$ composed of all ones, $\boldsymbol{A}^{+}$is Moore-Penrose pseudoinverse of the matrix $\boldsymbol{A}, c_{1}=-w$ and $c_{2}=\log C$ (Balda, 2011).

If we have to process data of $n \mathrm{SN}$ curves, the procedure was a bit different in the structure of matrices $\boldsymbol{A}$, and vectors $\boldsymbol{b}$, and $\boldsymbol{c}$, however, with the same form of solution (7), which is presented in Figure 1, (Balda, 2017a,b):

$$
\underbrace{\left[\begin{array}{ccccc}
\log \boldsymbol{s}_{a m_{1}} & \mathbf{1}_{a} & \mathbf{0}_{a} & \cdots & \mathbf{0}_{a} \\
\log \boldsymbol{s}_{a m_{2}} & \mathbf{0}_{a} & \mathbf{1}_{a} & \cdots & \mathbf{0}_{a} \\
\vdots & \vdots & \vdots & \ddots & \vdots \\
\log \boldsymbol{s}_{a m_{n}} & \mathbf{0}_{a} & \mathbf{0}_{a} & \cdots & \mathbf{1}_{a}
\end{array}\right]}_{\boldsymbol{A}} \underbrace{\left[\begin{array}{c}
-w \\
\log C_{m_{1}} \\
\log C_{m_{2}} \\
\vdots \\
\log C_{m_{n}}
\end{array}\right]}_{\boldsymbol{c}}=\underbrace{\left[\begin{array}{c}
\log \boldsymbol{N}_{a m_{1}} \\
\log \boldsymbol{N}_{a m_{2}} \\
\vdots \\
\log \boldsymbol{N}_{a m_{n}}
\end{array}\right]}_{\boldsymbol{b}},
$$


where $\mathbf{0}_{a}$ is a vector composed of all zeros and of the same dimension as $\boldsymbol{N}_{a m}$.

Examining the plot of a monotonic tension test from Figure 2, it is clear that there is only positive part of a fictive full cycle. It means that the tension test may be reckoned as a limiting case of the fatigue test, which has finished after $N=1 / 2$ cycles. An intercept of HCF SN curve with the line $N=1 / 2$ is a virtual elastic stress amplitude $s_{a m}^{\prime}$ defining the position of the SN curve in the figure. It might be accepted as a material constant, because it can serve for definition of $\mathrm{SN}$ curve in the form

$$
N_{a m}=\frac{1}{2}\left(\frac{s_{a m}^{\prime}}{s_{a}}\right)^{w}
$$

where the subscript $m$ means that the variable depends also on the mean stress $s_{m}$. Fictive amplitudes $s_{a m}^{\prime}$, intercepts of the parallel SN curves with the line $N=0.5$, were obtained from the formula

$$
s_{a m}=\left(\frac{C_{m}}{N_{a m}}\right)^{1 / w}, \quad \text { what gives for } N_{a m}=0.5 \quad\left(2 C_{m}\right)^{1 / w}=s_{a m}^{\prime},
$$

so $s_{a 450}^{\prime}=1193.952$ and $s_{a 600}^{\prime}=1044.711$. The difference of both values in MPa is

$$
s_{a 450}^{\prime}-s_{a 600}^{\prime}=149.241 \approx 150=s_{m_{2}}-s_{m_{1}} .
$$

Since the same behaviour has been proved also by other experiments, the conclusion is that the fictive amplitude of a material prestressed by $s_{m}$ can be evaluated from parameters of the Wöhler's curve as

$$
s_{a m}^{\prime}=s_{a 0}^{\prime}-s_{m} .
$$

This result is very valuable, because it avoids performing expensive and time consuming fatigue tests of prestressed material.

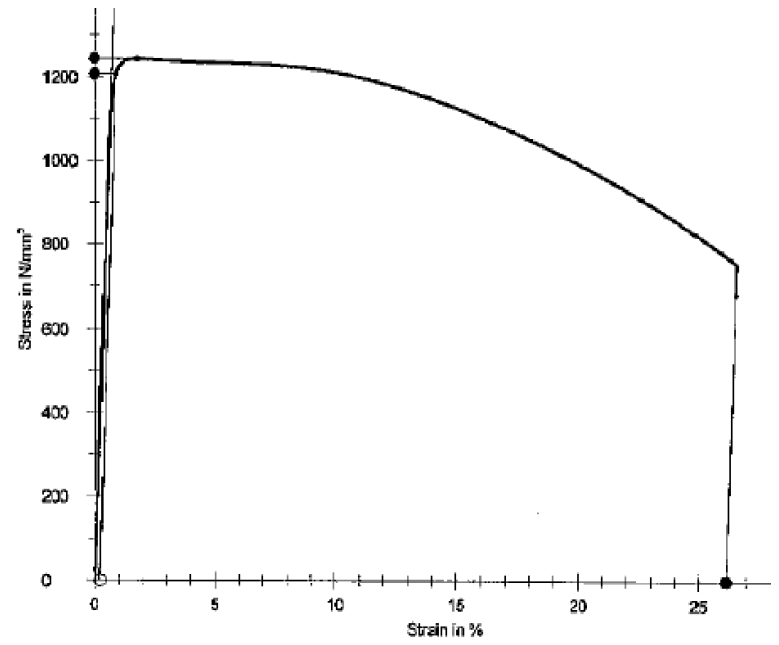

Fig. 2. Tensile test of T671

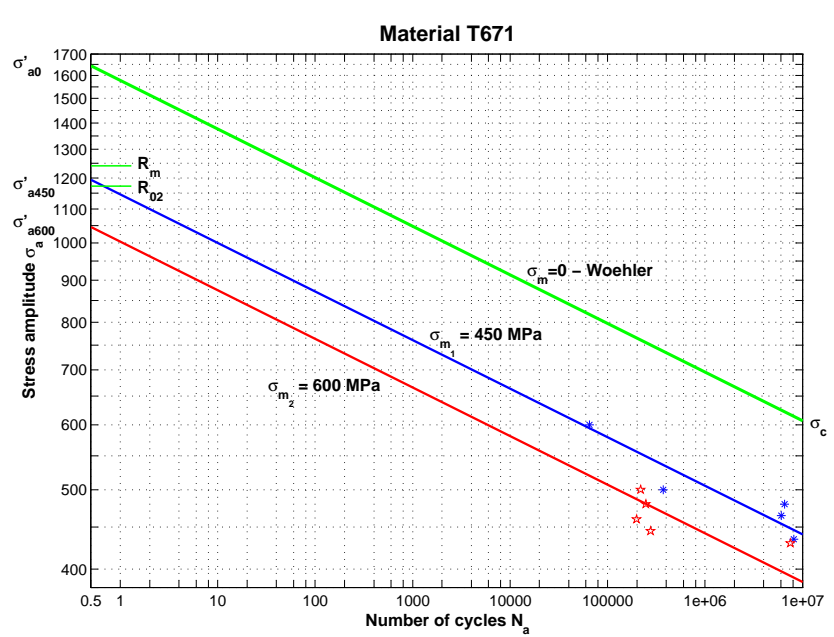

Fig. 3. Extended SN curves from Fig. 1

\section{Residual fatigue life}

An elementary damage developed by one stress full cycle can be estimated by an application of fatigue strength hypotheses, say, Pålmgren-Miner one (Pålmgren, 1924; Miner, 1945), designated also as a law of linear cumulation of damage, expresses the total relative damage as a sum of elementary damages $d_{a m}=$ $1 / N_{a m}$

$$
D=\sum_{\forall a m} \frac{1}{N_{a m}}=2 \sum_{\forall a m}\left(\frac{s_{a}}{s_{a m}^{\prime}}\right)^{w}=2 \sum_{\forall a m}\left(\frac{s_{a}}{s_{a 0}^{\prime}-s_{m}}\right)^{w} .
$$

The residual relative fatigue life is a scalar from a range $0-1, L=1-D$, where 1 belongs to the new object. It can be evaluated as soon as the rainflow decomposition of a stress process be finished (Nieslony, 2003). 


\section{Conclusions}

Unknown constraints existing among SN curves of prestressed materials possessing exponential law between fatigue life and stress amplitudes and that of free material have been discovered. Thanks to it, an knowledge of the common Wöhler's curve is sufficient for evaluation a damage generated by any stress cycle. No extra expensive fatigue tests of prestressed material are necessary.

The rainflow algorithm decomposing the complex stress sequence in critical places of an analyzed object into full- and half-cycles and their amplidudes and mean stresses, which are in conjunction with the Wöhler's curve fictive amplitude at the level $N_{a m}=0.5$ cycles sufficient to calculate the relative damage in each (half)cycle.

The processing of operational stress data by the new algorithm is fast and accurate that improves the reliability of the fatigue life forecast of the checked up structure. This fact enables better planning of the structure maintenance, a number of spare parts, and diminishes a danger of unexpected breakdowns.

\section{Acknowledgments}

The author appreciates a kind support of his research from the Centrum of Competence TE01020068 of the Technological Agency of the Czech Republic.

\section{References}

Balda, M. (2011) Vyhodnocování křivek životnosti. konf. Technical Computing, Humusoft, Prague

Balda, M. (2017) A new way for estimating fatigue damage of prestressed material, Workshop ZČU RTI Fatigue Life Assessment of Structures, University of West Bohemia - RTI, Plzeň, Dec 6-7

Balda, M. (2017) Life time curves, their structure and exploitation (In Czech), Rep. No. VYZ-VZ-36-17-059, VZU Plzeň, pp 1-15

Basquin, O.H. (1910) The Exponential Law of Endurance Tests, In Proceedings of American Society for Testing and Materials, ASTEA, Vol 10, pp. 625-630

Chvojan, J. (2003) Zkouška vysokocyklové únavy materiálu T671. VZÚ Plzeň, zkušební protokol č. 846/2003

ČSNI (1973) ČSN 420368 - Zkoušky únavy kovů. Statistické vyhodnocování výsledků zkoušek únavy kovů. Český normalizační institut, Praha

ČSNI (1978) ČSN 420310 - Zkouška tahem. Český normalizační institut, Praha

Eaton, J.W. et al. (2017) GNU Octave, A high-level interactive language for numerical computations. Free Your Numbers, version 4.2.1

MathWorks (1983-2017) MATLAB - The Language of Technical Computing. Corporate Headquarters 1 Apple Hill Drive, Natick, MA 01760-2098, US

Miner, M.A. (1945) Cumulative damage in fatigue, Trans. ASME, Journal of Applied Mechanics, (12) pp. A159-A164. Nieslony, A. (2003) Rainflow Counting Algorithm. MathWorks, File Exchange, file No. 3026

Pålmgren, A. (1924) Die Lebensdauer von Kugellagern, VDI Zeitschrift (68), pp. 339-341. 